\title{
Development and Validation of In Vitro Release Tests for Semisolid Dosage Forms-Case Study
}

\author{
Kailas D. Thakker, Ph.D., ${ }^{1}$ and Wendy H. Chern, Ph.D., ${ }^{2}$ \\ 1 President, Analytical Solutions, Raleigh, NC \\ 2 Director, Product Development, Dermik Laboratories, Aventis Pharmaceuticals, Inc., Berwyn, PA
}

email correspondence to: Kailast@aol.com or wendy.chern@aventis.com

\section{Background}

Historically, it has been challenging to carry out bioavailability/bioequivalence studies for semisolid drug product for the purpose of demonstrating the continued quality, efficacy and "sameness" of the product upon instituting certain changes in manufacturing process or substitution of excipients. Alternatively, in vitro tests such as determination of solubility, particle size, rate of release of the active ingredient and product homogeneity have been the main measures of product uniformity and quality equivalency. Among these, in vitro- release testing (IVRT) of active ingredient has drawn much attention as a result of the in issuance of the SUPAC-SS (Guidance for industry for nonsterile semisolid dosage forms) ${ }^{1}$. Many manufacturers of topical drugs have devoted significant resources to develop and validate IVRT during the drug product development process. However, as pointed out in a FIP/AAPS position paper ${ }^{2}$, there is no one standard test protocol that can be applied to all semisolid dosage forms.

A release test for retinoic acid in various semisolid formulations using Franz diffusion cells was developed. The products tested contained retinoic acid in novel formulations of either a cream or an ointment base. The IVRT was developed and validated using Retin- $A{ }^{\circledR}$ Cream because it is provided in different strengths and the release of retinoic acid from Retin- $A^{\circledR}$ products have been well studied ${ }^{3}$. The IVRT method was then applied to formulation development, and demonstrating the effect of process changes.

\section{Development of In Vitro Release Test}

\section{1) Assay Method:}

Although an assay method is normally available for the drug substance of interest and its related compounds, such method, as is, may not be suitable for the analysis of these compounds in the selected receiving medium. In most cases, a certain degree of method modification and a complete validation of the modified method are required in order to ensure the quality of IVRT results. The assay method was modified (originally validated for retinoic acid and its related compounds) in order to quantify low levels of retinoic acid in the receiving medium, phosphate buffer (pH 5.5) containing 30-35\% of ethanol, which was shown to be the appropriate range of organic phase for release of retinoic acid (page 11).

\section{2) Selection of Membrane:}

The membrane selected should provide an inert holding surface for the test formulation, but not a barrier. The membrane of choice should allow the active ingredient to readily diffuse into the receiving medium as it is "released" from the dosage form. It is important to confirm that there is no interaction, physical or chemical between the membrane and the formulation. The excipients present in the formulation may affect the physical integrity of the membrane, or, in many cases, the active ingredient may bind to the membrane. Additionally, the membrane should not contain any "leachables" that can cause interference to the assay of the active ingredient. A battery of membranes was included in the beginning of the method development:Commonly used membranes are- Tuffryn, ${ }^{\circledR}$ Supor ${ }^{\circledR}$ (polysulphone), Cellulosic, Acetate Plus ${ }^{\circledR}$ (cellulose acetate) Nylon, Teflon, and Polycarbonate. It is recommended that standard solutions of the test compound in the receiving medium be prepared at a couple of concentration levels, in the upper and lower concentration ranges expected in the IVRT experiment, to verify the extent of drug binding to the membrane. Commercially available filter cartridges were assembled with the tested membrane filters. Standard solutions of retinoic acid were passed through these membrane filters, and the "filtered" standard solutions were analyzed for retinoic acid recovery.

For retinoic acid containing formulations, drug concentrations of 0.1 and $0.02 \mu \mathrm{g} / \mathrm{ml}$ were selected for testing based on literature reference. Among membranes screened, polysulphone membranes (Tuffryn ${ }^{\circledR}$ and Supor ${ }^{\circledR}$ ) showed a significant retention of retinoic acid at low levels $(0.02 \mu \mathrm{g} / \mathrm{ml})$. Acetate Plus ${ }^{\circledR}$ membrane showed best recovery with no positive interference by HPLC (Table 1). Therefore, AcetatePlus ${ }^{\circledR}$ was chosen for further development and validation.

Pretreatment of the membrane by soaking in the receiving medium and/or $0.5 \%$ isopropyl myristate was recommended by many investigators. However, for retinoic acid formulations, pre-treatment of the membrane had little or no effect on the overall release profile.

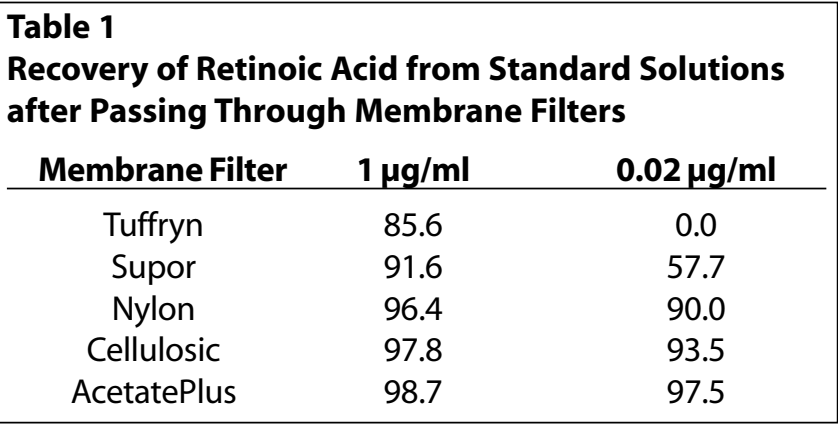




\section{3) Selection of Receiving Medium:}

Although it is desirable to have a receiving medium that is similar to the physiological condition of the skin, it is also imperative to ensure that the release of the drug can be measured without bias. The most important factor for the selection of receiving medium is the solubility of the active ingredient in the medium. The receiving medium should provide a "diffusional sink" for the active ingredient released from the semisolid formulation. The relationship of $\mathrm{Q}$ (cumulative amount released) versus $\sqrt{T}$ (square root of time) is derived from the Higuchi model ${ }^{4}$ with the assumption that there is a reservoir of the drug always available to diffuse thru. As a rule of thumb, there should be no more than $30 \%$ of the total amount of the dose applied released into the medium at the end of the experiment.

The $\mathrm{pH}$ of the medium is also an important factor for consideration. Selection of the $\mathrm{pH}$ of the aqueous component of the medium should be based on the $\mathrm{pH}$ of the formulation, $\mathrm{pH}$-solubility profile of the active ingredient and the $\mathrm{pH}$ of the target membrane.

One practical consideration is to choose a receiving medium that allows sufficient amounts of active ingredient released within a reasonable time period to ensure accurate analysis of the release rate samples.

The solubility of retinoic acid in ethanolic-buffered media is sufficient to meet all of the requirements discussed above. After a few preliminary experiments, a pH 5.5-phosphate buffer with 35\% ethanol was selected as the receiving medium. Phosphate buffer with $35 \%$ ethanol allowed sufficient levels of retinoic acid to diffuse through the membrane from prototype formulations for accurate analysis of retinoic acid. Parallel testing of several investigational formulations were carried out using $\mathrm{pH} 3.5$ and $\mathrm{pH} 5.5$ buffers, which were the $\mathrm{pH}$ of the tested formulation and skin $\mathrm{pH}$, respectively. Release profiles of the reference product, Retin- $A^{\circledR} 0.025 \%$ cream showed higher release of retinoic acid in $\mathrm{pH} 5.5$ buffer, while certain prototype formulations ( 8 \& 9) showed little difference in the release of retinoic acid into buffered receiving media of either $\mathrm{pH}$ (Table 2). The $\mathrm{pH} 5.5$ buffer: ethanol $(65: 35 \mathrm{v} / \mathrm{v})$ was used as the receiving medium for further experiments.

Small changes in alcohol concentration did not result in significant changes in rate of release of retinoic acid from Retin- $A^{\circledR}$ Cream. (Figure 1).

\begin{tabular}{|c|c|c|}
\hline \multicolumn{3}{|c|}{$\begin{array}{l}\text { Table } 2 \\
\text { Average Rate of Release* of Retinoic Acid ( } \mu \mathrm{g} / \mathrm{cm}^{2} / \mathrm{hours}^{1 / 2} \text { ) fror } \\
\text { Investigational Retinoic Acid Formulations }\end{array}$} \\
\hline $\begin{array}{l}\text { Formulations } \\
\text { Tested }\end{array}$ & $\begin{array}{l}\text { Release Rate* in pH } 3.5 \\
\text { Phosphate Buffer: } \\
\text { Ethanol 65:35 v/v }\end{array}$ & $\begin{array}{l}\text { Release Rate* in pH } 5.5 \\
\text { Phosphate Buffer: } \\
\text { Ethanol 65:35 v/v }\end{array}$ \\
\hline 1 & 0.374 & 0.141 \\
\hline 2 & 0.040 & 0.034 \\
\hline 3 & 0.106 & 0.040 \\
\hline 4 & 0.478 & 0.290 \\
\hline 5 & 0.091 & 0.087 \\
\hline 6 & 0.139 & 0.041 \\
\hline 7 & 0.241 & $--^{* *}$ \\
\hline 8 & 0.353 & 0.327 \\
\hline 9 & 0.052 & 0.054 \\
\hline
\end{tabular}

${ }^{*}$ Average slope of the line where square root of time (hours ${ }^{1 / 2}$ ) is the $x$-axis and cumulative amount released $\left(\mathrm{ug} / \mathrm{cm}^{2}\right)$ is the $y$-axis.

** Poor release, slope cannot be calculated

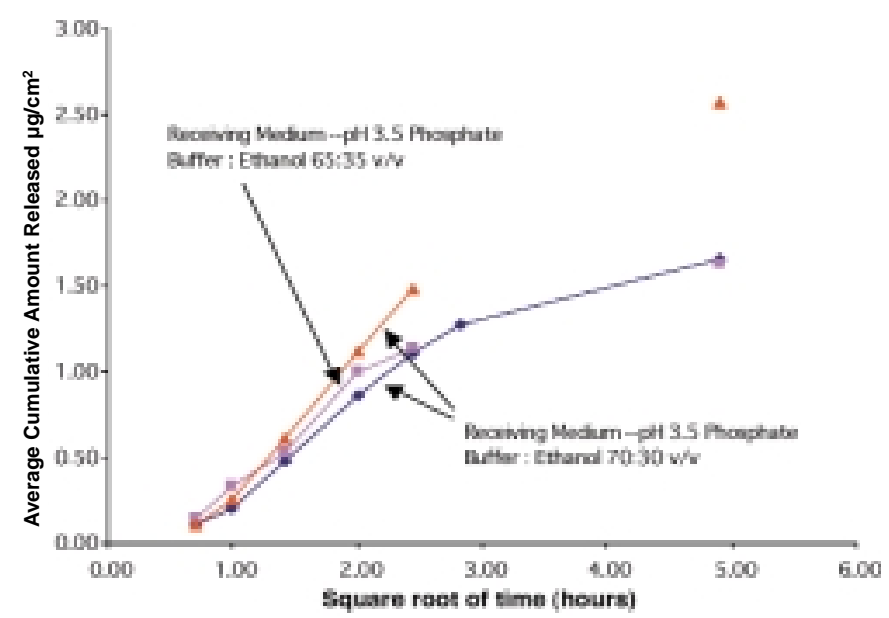

Figure 1: Average Release of Retinoic Acid from 0.025\% Retin- $A^{\circledR}$ Cream Through Acetate Plus Membrane into Ethanolic Buffered Media.

\section{4) Selection of Equipment Related Parameters and Calculation of Drug Release:}

The following specific equipment related parameters are to be considered in developing a release test.

Apparatus: Generally, six Franz diffusion cells are used for a test as in dissolution testing to nullify individual dosage form variability.

Temperature: In most cases where the dosage form is applied to skin, $32^{\circ} \mathrm{C}$ is appropriate. Exceptions are when the target organ is a membrane such as vaginal mucosa, in which case, $37^{\circ} \mathrm{C}$ is more appropriate. We used $32^{\circ} \mathrm{C}$ in all the experiments.

Sampling Intervals: $0.5,1,2,4,6,8$ (optional) 24 and 48 hours (optional). 


\section{Semi-Solid Dosage Forms... continued}

Sampling Volume: $200 \mu \mathrm{l}$ at each time point with volume replaced with fresh medium every time.

Calculations:

The cumulative amount $(\mathrm{Q})$ of retinoic acid released per surface area of membrane is:

$$
\mathrm{Q}=\left\{\mathrm{C}_{\mathrm{n}} \mathrm{V}+\sum_{\mathrm{i}=1}^{\mathrm{n}-1} \mathrm{Ci} S\right\} / \mathrm{A}
$$

Where

$$
Q=\begin{aligned}
& \text { Cumulative amount of retinoic acid released per } \\
& \text { surface area of membrane }\left(\mu \mathrm{g} / \mathrm{cm}^{2}\right)
\end{aligned}
$$

$C_{n}=$ Concentration of retinoic acid $(\mu \mathrm{g} / \mathrm{ml})$ determined at nth sampling interval.

$\mathrm{V}=$ Volume of individual Franz diffusion cell

$\mathrm{n}-1$

$\sum C_{i}=$ Sum of concentrations of retinoic acid $(\mu \mathrm{g} / \mathrm{ml})$

$\mathrm{i}=1$ determined at sampling intervals 1 through $\mathrm{n}-1$

$\mathrm{S}=$ Volume of sampling aliquot, $0.2 \mathrm{ml}$

\section{$A=$ Surface area of sample well. For this work, the} surface area was $1.767 \mathrm{~cm}^{2}$

Validation of the In Vitro Release Test Developed for Retinoic Acid Formulations:

Normally, "failure formulations" with known deficiencies are required to perform the validation. In this case, the method was first validated using marketed product, Retin$A^{\circledR}$ Cream, then applied to the investigational formulations with known differences to confirm the ability of this method to differentiate between formulations containing variables under exploration.

The attributes validated were:

1) Reproducibility:Cell-to-cell variability and criteria used to accept/reject individual data

2) Accuracy: "Sameness" among batches of the same composition tested at different times.

3) The effect of dosage strength on the rate of release

4) The effect of changes in composition on the rate of release

5) The effect of changes in process parameters on the rate of release

6) The effect of changes in viscosity of the dosage form on rate of release

1) Reproducibility: Cell-to-cell variability and criteria used to accept/reject individual data

In absence of calibrators for the Franz diffusion cell apparatus, an in-house standard, Retin- $A^{\circledR}$ Cream $0.025 \%$ was used as reference. Additionally, the slope and correlation coefficients for the line described by the square root of time ( $x$-axis) and the cumulative amount released per surface area (y-axis) were calculated for each cell daily. The line with correlation coefficient $<0.98$ was rejected.

\section{2) Accuracy: "Sameness" among batches of the same} composition tested at different times.

Different batches of investigational retinoic acid formulation lots with identical composition, prepared by the same process yielded very comparable slope values on several occasions. Table 3 shows one example.

\section{3) The Effect of Dosage Strength on The Rate of Release:}

IVRT of retinoic acid in Retin- $A^{\circledR}$ Creams $0.025 \%, 0.05 \%$ and $0.1 \%$ were determined using the conditions described above. Figure 2 shows the release profile of retinoic acid from these formulations. The release rate and the total amount of drug released are proportional to the strength of the Retin- $A^{\circledR}$ Cream in ethanol $65 / 35(\mathrm{v} / \mathrm{v})$ : $\mathrm{pH} 5.5$ phosphate buffer: ethanol $(65: 35 \mathrm{v} / \mathrm{v})$.

Figure 3 (page 14) shows the release profiles of three lots of the same investigational retinoic acid formulations, two at $0.025 \%$ and one at $0.05 \%$ drug concentration. The same dose proportionality, as seen in Retin- $A^{\circledR}$ Creams, was observed here, although the initial rate of release is slower.

Table 3. Average Flux $\left(\mu \mathrm{g} / \mathrm{cm}^{2} / \mathrm{hrs}^{1 / 2}\right)$ for Investigational Retinoic Acid Formulations: "Sameness" in Release Profile and Slope for the Same Product

\begin{tabular}{ccc} 
Batch & $\begin{array}{c}\text { Retinoic Acid } \\
(\mathbf{w} / \mathbf{w})\end{array}$ & $\begin{array}{c}\text { Flux } \\
\left(\boldsymbol{\mu g} / \mathbf{c m}^{2} / \mathbf{h r}{ }^{\mathbf{1}}{ }^{1 / 2}\right)\end{array}$ \\
\hline 1 & $0.025 \%$ & 0.289 \\
2 & $0.025 \%$ & 0.278 \\
*Average slope of the line where square root of time $($ hours & \\
the x-axis and cumulative amount released $\left(\mu \mathrm{g} / \mathrm{cm}^{2}\right)$ & is the $y$-axis. \\
\hline
\end{tabular}

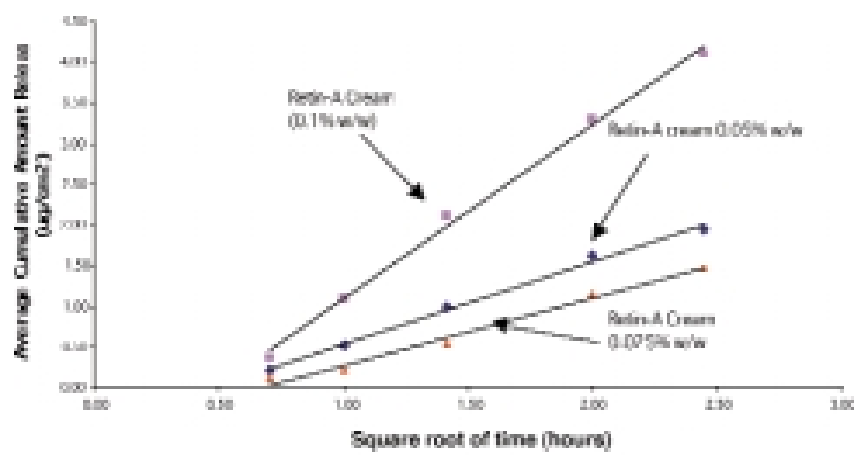

Figure 2: Average $(n=6)$ Rate of Release of Retinoic Acid from Retin- $A^{\circledR}$ Creams of Different Strengths Through Acetate Plus ${ }^{\circledR}$ Membrane into $\mathrm{pH} 5.5$ Phosphate Buffer: Ethanol 65:35 v/v 
Therefore, the linear correlation between the average cumulative amounts of released drug versus square root of time exists after the first hour of the test.

\section{4) The Effect of Changes in Composition on the Rate of Release:}

Figure 4 shows the release of retinoic acid from two $0.025 \%$ strength formulations These formulations were

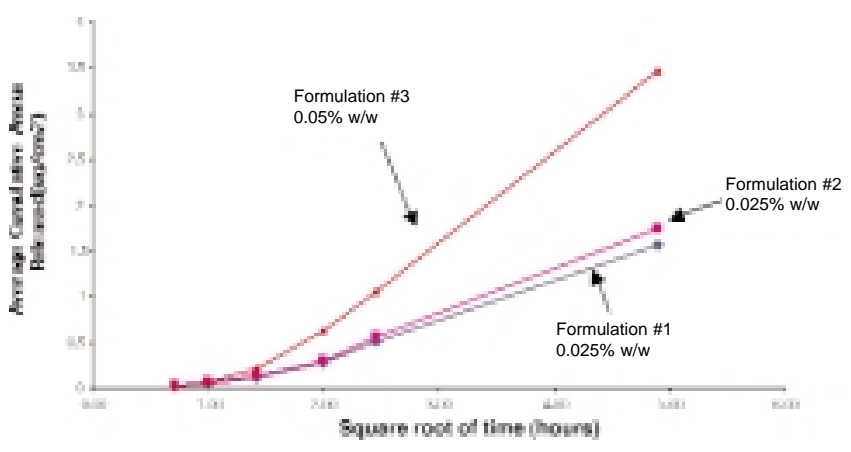

Figure 3: Average ( $n=6)$ Rate of Release of Retinoic Acid from Investigational Retinoic Acid Formulations of Different Strengths Through Acetate Plus ${ }^{\circledR}$ Membrane into $\mathrm{pH} 5.5$ Phosphate Buffer: Ethanol 65:35 v/v

manufactured by the same process. Practically no retinoic acid was released from Formulation 1 while a significant amount of retinoic acid was released from Formulation 2, Formulation 2 contained twice the amount of emollient and additional modifiers.

Figures 5-7 show the release of retinoic acid from three pairs of investigational prototype formulations where the only difference between the formulations was the presence and absence of penetration enhancer. While in Figures 5 and 6 , higher release of retinoic acid was observed with the added ingredient, for formulations in Figure 7, the release between the two formulations was not significantly different. Note that there were differences in the viscosity of these formulations, which might have had a confounding

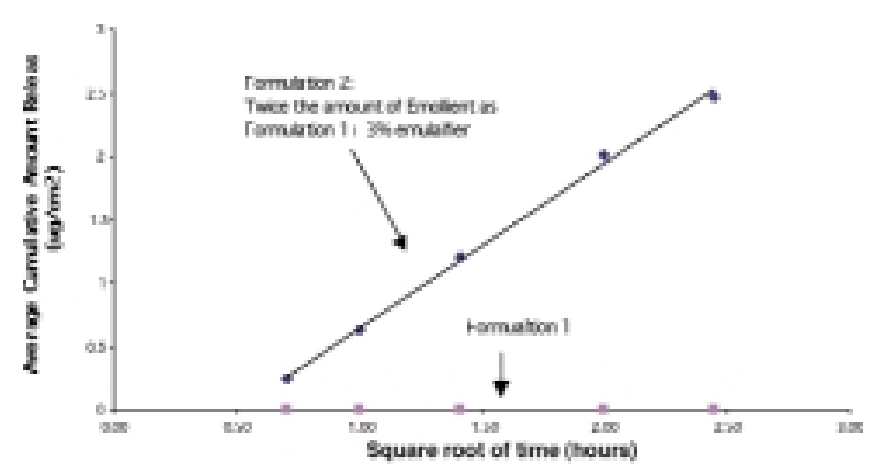

Figure 4: Average Release of Retinoic Acid from Two Investigational Retinioc Acid Formulations $(0.025 \% \mathrm{w} / \mathrm{w}$ ) Manufactured by the same Process With Different Compositions.

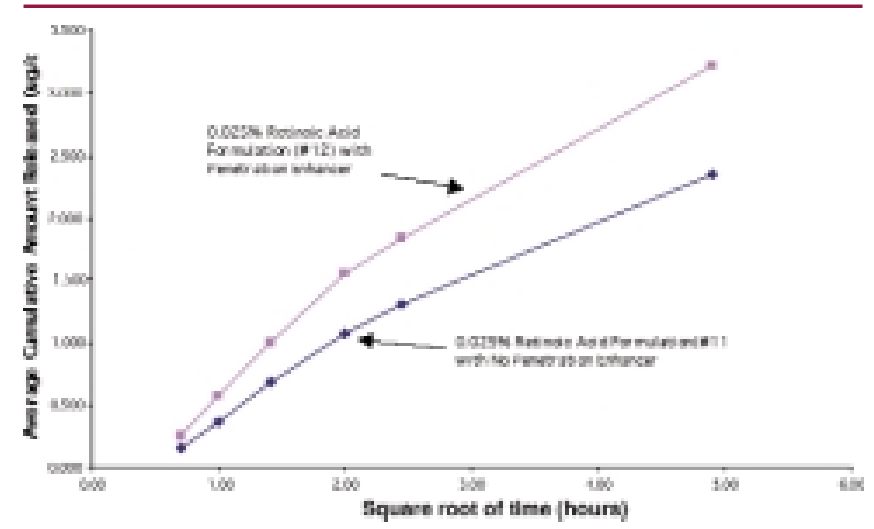

Figure 5: Average Release of Retinoic Acid from Two Investigational Retinioc Acid Formulations $(0.025 \% \mathrm{w} / \mathrm{w}$ ) Manufactured by the same Process With Different Compositions: Effect of Penetration Enhancer

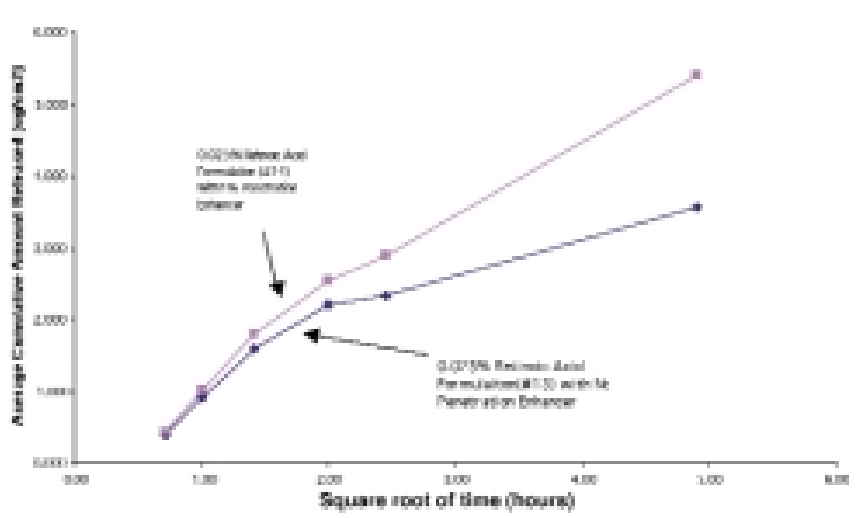

Figure 6: Average Release of Retinoic Acid from Two Investigational Retinoic Acid Formulations $(0.025 \% \mathrm{w} / \mathrm{w}$ ) Manufactured by the same Process With Different Compositions: Effect of Penetration Enhancer

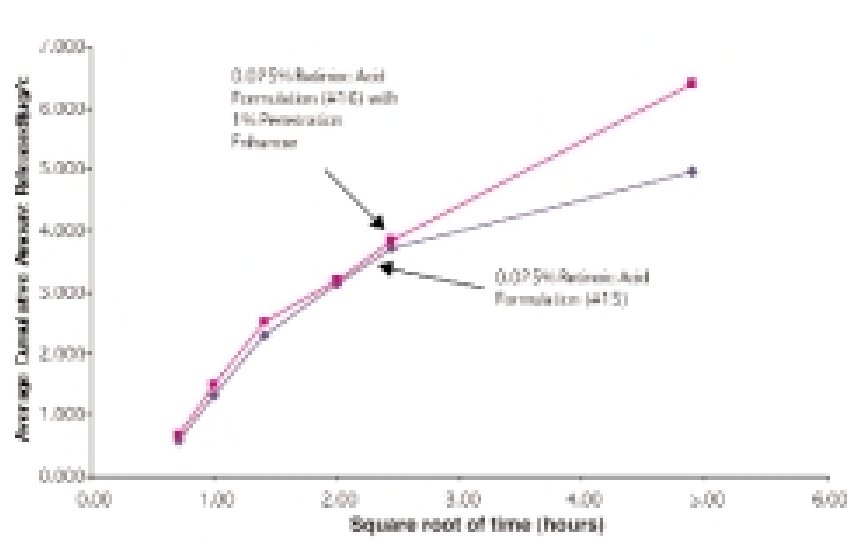

Figure 7: Average Release of Retinoic Acid from Two Investigational Retinoic Acid Formulations $(0.025 \% \mathrm{w} / \mathrm{w}$ ) Manufactured by the same Process With Different Compositions: Effect of Penetration Enhancer.

effect on the drug release. (See discussion below.)

\section{5) The Effect of Changes in Process Parameters on The Rate of Release:}

Table 4 shows two pairs of formulations in which retinoic 


\section{Semi-Solid Dosage Forms... continued}

acid was either completely dissolving directly into the oil phase, or pre-dissolved in an organic solvent. The release of retinoic acid was greater when the drug was incorporated by pre-dissolving in organic solvent, completely or partially.

Scale-up from laboratory to the production scale is a variable that must be evaluated. For the investigational formulations, the scale-up from $3 \mathrm{KG}$ to $100 \mathrm{KG}$ batch did not affect the rate of release for prototype for Formulation 3 , but had a significant effect on the prototype Formulation 2.

Table 5 shows a comparison of the drug release from prototype formations manufactured at different scales.

\section{6) Effect of Viscosity Changes on The Rate of Release:} Viscosity is one of the key attribute for semisolid dosage forms. A significant impact of viscosity changes on the release of retinoic acid from the investigational formulations was observed. Tables 6 and 7 show the effect of the viscosity builder on the drug release from these formulations. In Table 6, prototype formulations 1-4,5-7 and 8-11 all show a similar trend that the release of retinoic acid was inversely proportional to the amount of viscosity builder in the formulation.

In Table 7, prototype formulations 1 to 6 show the combinational effect of compositional changes and viscosity changes on the release of retinoic acid. Impact on the release profile was apparent for Formulation pairs 1-2 and 3-4, while it less evident between Formulations 5 and 6 (See Figures 5-7). Nevertheless, the viscosity differences between formulations 1 and 2,3 and 4, as well as 5 and 6 all showed a similar trend that the drug release is inversely proportional to the amount of viscosity builder in the formulation.

\begin{tabular}{cccc} 
Formulation & $\begin{array}{c}\text { Retinoic Acid } \\
(\mathbf{w} / \mathbf{w})\end{array}$ & $\begin{array}{c}\text { Drug Dissolved In } \\
(\boldsymbol{\mu g} / \mathbf{c m} \mathbf{2} / \mathbf{h r}-\mathbf{1} / \mathbf{2})\end{array}$ & Average Flux* \\
\hline $1-\mathrm{A}$ & $0.05 \%$ & $\begin{array}{c}100 \% \text { pre-dissolved } \\
\text { in organic solvent }\end{array}$ & 0.189 \\
\hline $1-\mathrm{B}$ & $0.05 \%$ & $\begin{array}{c}40 \% \text { dissolved directly } \\
\text { into oil phase, } \\
60 \% \text { predissolved } \\
\text { in organic solvent }\end{array}$ & 0.110 \\
\hline $2-\mathrm{A}$ & $0.05 \%$ & $\begin{array}{c}100 \% \text { directly into } \\
\text { the oil phase }\end{array}$ & 0.603 \\
\hline $2-\mathrm{B}$ & $0.05 \%$ & $\begin{array}{c}100 \% \text { pre-dissolved } \\
\text { in organic solvent }\end{array}$ & 1.406 \\
\hline
\end{tabular}

${ }^{*}$ Average slope of the regression line where square root of time (hours ${ }^{1 / 2}$ ) is the $x-$ axis and cumulative amount released $\left(\mu \mathrm{g} / \mathrm{cm}^{2}\right)$ is the $y$-axis.

Table 5. Average Flux $\left(\mu \mathrm{g} / \mathrm{cm}^{2} / \mathrm{hrs}^{1 / 2}\right)$ for Investigational Retinoic Acid Formulations: Effect of Scale-up on Rate of Release

\begin{tabular}{|c|c|c|c|}
\hline Formulation & Lot \# & Average Flux* & $\begin{array}{c}\begin{array}{c}\text { Total Amount Released } \\
\left(\mu \mathrm{g} / \mathrm{cm}^{2} / \mathrm{hr}-1 / 2\right)\end{array} \\
\text { After } 6 \text { Hours }(\mathrm{mg}) \pm \text { Std. Deviation }\end{array}$ \\
\hline \multirow[t]{2}{*}{1} & $\mathrm{~A}(3 \mathrm{KG})$ & 0.347 & $1.200 \pm 0.071$ \\
\hline & $\mathrm{B}(100 \mathrm{KG})$ & 0.406 & $1.412 \pm 0.028$ \\
\hline \multirow[t]{2}{*}{2} & $\mathrm{~A}(3 \mathrm{KG})$ & 0.054 & $0.145 \pm 0.021$ \\
\hline & $\mathrm{B}(100 \mathrm{KG})$ & $--^{* *}$ & $0.020 \pm 0.013$ \\
\hline \multirow[t]{2}{*}{3} & $\mathrm{~A}(3 \mathrm{KG})$ & 0.290 & $0.855 \pm 0.140$ \\
\hline & $\mathrm{B}(100 \mathrm{KG})$ & 0.258 & $0.799 \pm 0.085$ \\
\hline
\end{tabular}

*Average slope of the line where square root of time (hours ${ }^{1 / 2}$ ) is the $x$-axis and cumulative amount released $\left(\mu \mathrm{g} / \mathrm{cm}^{2}\right)$ is the $y$-axis.

**Insignificant release for first six hours, cannot calculate the slope.

\section{Conclusions:}

1) IVRT of retinoic acid was shown to differentiate changes in the composition, certain manufacturing process and viscosity of the processor formulations.

2) IVRT developed for retinoic acid formulation provides a useful tool to assess the drug product quality and "sameness" as required by SUPAC-SS

3) It should be noted that IVRT is only "valid" for those parameters that were tested.

4) Experiments such as, effect of the back-diffusion of alcohol ( $\mathrm{n}$ the receiving medium) into the formulation and "sensitivity" of the method (minimal discriminating concentration differences) for each variant-must be specifically determined as part of a complete method validation.

Acknowledgments:

The authors wish to thank the following individuals for their assistance: Minh Lam,Tamra Meyer, Louis DeLaine, Dev Chatterji, Jack Southard and Gamal Norton. 


\begin{tabular}{|c|c|c|c|}
\hline \multicolumn{4}{|c|}{$\begin{array}{l}\text { Table } 6 . \text { Average Flux }\left(\mu \mathrm{g} / \mathrm{cm}^{2} / \mathrm{hrs}^{1 / 2}\right) \text { for Investigational } \\
\text { Retinoic Acid Formulations: Effect of Viscosity Changes on } \\
\text { Rate of Release }\end{array}$} \\
\hline Formulation & $\begin{array}{c}\text { Viscosity Builder } \\
(\% w / w)\end{array}$ & $\underset{\mu \mathrm{g} / \mathrm{cm}^{2} / \mathrm{hr}-1 / 2}{\text { Flux }^{*}}$ & $\begin{array}{l}\text { Total Amount Released } \\
\text { After Six Hours (mg) }\end{array}$ \\
\hline 1 & 10 & 0.406 & 1.412 \\
\hline 2 & 10 & 0.347 & 1.200 \\
\hline 3 & 5 & 1.391 & 4.766 \\
\hline 4 & 0 & 2.134 & 7.287 \\
\hline 5 & 10 & 0.258 & 0.799 \\
\hline 6 & 10 & 0.290 & 0.855 \\
\hline 7 & 0 & 1.473 & 4.458 \\
\hline 8 & 10 & $--^{* *}$ & 0.020 \\
\hline 9 & 10 & 0.054 & 0.145 \\
\hline 10 & 10 & 0.084 & 0.256 \\
\hline 11 & 0 & 0.078 & 0.231 \\
\hline
\end{tabular}

*Average slope of the line where square root of time (hours ${ }^{1 / 2}$ ) is the $x$ axis and cumulative amount released $\left(\mu \mathrm{g} / \mathrm{cm}^{2}\right)$ is the $y$-axis.

**Insignificant release for first six hours, cannot calculate the slope.

\section{Table 7. Average Flux $\left(\mu \mathrm{g} / \mathrm{cm}^{2} / \mathrm{hrs}^{1 / 2}\right)$ for Investigational Retinoic Acid Formulations: Effect of Viscosity Changes on Rate of Release}

\begin{tabular}{|c|c|c|}
\hline Formulation & Ingredients & $\begin{array}{c}\text { Average Flux } \\
\left(\mu \mathrm{gg} / \mathrm{cm}^{2} / \mathrm{hr}-1 / 2\right)^{*}\end{array}$ \\
\hline 1 & $\begin{array}{l}\text { 10\% Viscosity Builder } \\
\text { Without penetration enhancer }\end{array}$ & 0.67 \\
\hline 2 & $\begin{array}{c}10 \% \text { Viscosity Builder, } \\
\text { With } 1 \% \text { penetration enhancer }\end{array}$ & 0.92 \\
\hline 3 & $\begin{array}{c}5 \% \text { Viscosity Builder } \\
\text { Without penetration enhancer }\end{array}$ & 1.14 \\
\hline 4 & $\begin{array}{l}5 \% \text { Viscosity Builder, } \\
\text { With } 1 \% \text { penetration enhancer }\end{array}$ & 1.42 \\
\hline 5 & $\begin{array}{l}\text { 3.6\% Viscosity Builder } \\
\text { Without penetration enhancer }\end{array}$ & 1.52 \\
\hline 6 & $\begin{array}{c}\text { 3.6\% Viscosity Builder, } \\
\text { With } 1 \% \text { penetration enhancer }\end{array}$ & 1.76 \\
\hline
\end{tabular}

*Average slope of the line where square root of time (hours $1 / 2$ ) is the $x$-axis and cumulative amount released $(\mathrm{ug} / \mathrm{cm} 2)$ is the $y$-axis
Direct Correspondence to:

Kailas D. Thakker, Ph.D.

President, Analytical Solutions Inc., 2431-131

Spring Forest Road, Raleigh NC 27615

Wendy H. Chern, Ph.D.

Director, Product Development, Dermik Laboratories, Aventis Pharmaceuticals, Inc., 1050 Westlake Drive, Berwyn PA 19312

\section{References:}

1) FDA Guidance for Industry: SUPAC-SS Nonsterile Semisolid Dosage Forms. Scale-Up and Postappraoval Changes: Chemistry, Manufacturing, and Controls; In Vitro Release Testing and In Vivo Bioequivalence Documentation, May 1997.

2) M Siewert, J Dressman, C Brown and VP Shah, FIP/AAPS Guidelines for Dissolution/ In Vitro Release Testing of Novel/Special Dosage Forms. Dissolution Technologies Volume 10 Issue 1 February 2003

3) M. Corbo, R. Partak, J. Marvel, S. Ng, T. Schultz, G. Van Buskirk, Utility of in Vitro Release Testing Methods for Semi-solid Formulations in which the active is fully solubalized. In Vitro Release of Tretinoin from an O/W Cream. Pharmaceutical Research (1994) Vol. 11, No 10 Suppl, pp $\mathrm{S} 12$

4) T. Higuchi, Physical Chemical Analysis of Percutaneous Absorption Process from Creams and Ointments. J. Soc. Cosmetic Chemistry, Vol 11, 85 (1960) 